Western New England University School of Law

Digital Commons @ Western New England University School of Law

Faculty Scholarship

Faculty Publications

2018

\title{
Removing Obstacles to a Peaceful Death
}

Kathy L. Cerminara

Nova Southeastern University

Barbara A. Noah

Westen New England University School of Law, bnoah@law.wne.edu

Follow this and additional works at: http://digitalcommons.law.wne.edu/facschol

Part of the Elder Law Commons, Health Law and Policy Commons, and the Medical Jurisprudence Commons

\section{Recommended Citation}

Kathy L. Cerminara \& Barbara A. Noah, Removing Obstacles to a Peaceful Death, 25 ELDER L.J. 197 (2018).

This Article is brought to you for free and open access by the Faculty Publications at Digital Commons @ Western New England University School of Law. It has been accepted for inclusion in Faculty Scholarship by an authorized administrator of Digital Commons @ Western New England University School of Law. For more information, please contact pnewcombe@law.wne.edu. 


\title{
REMOVING OBSTACLES TO A PeACEFul DeATH
}

\author{
Kathy L. Cerminara \\ Barbara A. Noah
}

We all will die, but the American health care system often impedes a peaceful death. Instead of a quiet death at home surrounded by loved ones, many of us suffer through overutilization of sometimes-toxic therapeutic interventions long past the time when those interventions do more good than harm. This article proposes revisions to health professional training and payment policy to eliminate as much as possible physical and existential suffering while progressing through the terminal phase of illness. The solution lies in seamless progression from treatment with integrated palliative care to hospice before death, but provider attitudes and payor practices must change for that to occur. Thus, the article proposes increased training in communicating truthfully about prognosis and prospective benefit of therapies; further adoption of interprofessional practice, which would familiarize more professionals with the teambased approach characteristic of palliative care; and revision of payment mechanisms to incentivize high-quality care whether it is of low or high intensity.

Kathy L. Cerminara is Professor of Law, Nova Southeastern University, Shepard Broad College of Law. Professor Cerminara thanks her research assistants Elan Neuman, Anca Oprea, Antoinette Pollard, and Erica Lohlein Rudolf.

Barbara A. Noah is Professor of Law, Western New England University School of Law and past Schulich Distinguished Visiting Scholar, Dalhousie University Schulich School of Law (2017). 


\section{Introduction}

The longer life expectancies that have resulted from widely available preventive medical care have led to an increasingly aging population and, consequently, larger numbers of people who die from illnesses such as cancer, stroke, heart disease, and dementia. This growth in the older population in turn places pressure on the health care system to care for an increasing number of older, seriously ill adults. Yet, in a medical system that still focuses on treatment and cure and that tends to deliver acute and intensive interventions even near the end of life, palliative and hospice care remain underutilized. ${ }^{2}$ These patterns are even more pronounced among racial and ethnic minorities, ${ }^{3}$ but nearly all segments of the population near the end of life could benefit from increased and earlier access to palliative and hospice care. The concurrent overutilization of therapeutic care and life-prolonging technologies in dying patients results in many situations in which patients suffer unnecessarily from adverse effects and other sorts of iatrogenic harm. ${ }^{4}$

1. See Mark Mather, Fact Sheet: Aging in The United States, POPULATION REFERENCE BUREAU, http://www.prb.org/Publications/Media-Guides/2016/ aging-unitedstates-fact-sheet.aspx ("The number of Americans ages 65 and older is projected to more than double from 46 million today to over 98 million by 2060, and the 65-and-older age group's share of the total population will rise to nearly 24 percent from 15 percent." ); see also Donna L. Hoyert, 75 Years of Mortality in the United States: 1935-2012, CTR. FOR DISEASE CONTROL AND PREVENTION (Mar. 2012), http:/ / www.cdc.gov/nchs/data/databriefs/ db88.htm\#x2013;2010</a (finding that heart disease, cancer, and stroke remain among the top five causes of death).

2. See Haiden A. Huskamp et al., Discussions with Physicians About Hospice Among Patients with Metastatic Lung Cancer, 169 ARCHIVES OF INTERNAL MED. 954, 955-56 (2009) (finding that only half of patients with stage IV lung cancer had any discussion with their physicians about hospice in the two months prior to death); Joan M. Teno et al., Change in End-of-Life Care for Medicare Beneficiaries: Site of Death, Place of Care, and Health Care Transitions in 2000, 2005, and 2009, 309 J. AM. MED. $\mathrm{Ass}^{\prime} \mathrm{N}$ 470, 474 (2013) (noting that, although the use of hospice services has increased during the early $2000 \mathrm{~s}$, only $42.2 \%$ of Medicare beneficiaries with dementia and $59.5 \%$ of Medicare beneficiaries with cancer received hospice services at the time of death) [hereinafter Teno].

3. Alina M. Perez \& Kathy L. Cerminara, La Caja de Pandora: Improving Access to Hospice Care Among Hispanic and African-American Patients, 10 HOUS. J. HEALTH L. \& POL'Y 255, 260-88 (2010) [hereinafter Perez \& Cerminara]; see generally Barbara A. Noah, The Role of Race in End-of-Life Care, 15 J. HEALTH CARE L. \& POL'Y 344, 349 78 (2012) [hereinafter Noah].

4. See Corita Grudzen \& Deborah Grady, Improving Care at the End of Life, 171 ARCHIVES OF INTERNAL MED. 1202, 1202 (2011) (discussing over-use of therapeutic interventions at the end of life and advocating that better-quality care often requires emphasizing palliative measures and avoiding unavailing therapies that risk unnecessary suffering and iatrogenic harm); see also infra notes 8 to 15 and accompanying text (providing further documentation and discussion of the overutilization problem). 
In current medical practice, palliative care provided prior to hospice care is reimbursed by a different mechanism from hospice care. ${ }^{5}$ This segregated reimbursement mechanism perpetuates a variety of misconceptions about palliative and hospice care. These misconceptions in turn contribute to the underutilization of palliative care. Part of the solution to increasing utilization of palliative and hospice care is to remove the artificial dividing line in terms of both payment and perception between therapeutic and palliative care and to focus instead on training health care professionals to integrate the two. ${ }^{6}$ In addition, for terminally ill patients, palliative and hospice care should function together seamlessly as a continuum of interventions appropriate to each stage of the illness rather than as two separate steps, and palliative care should commence as soon as it potentially could benefit the patient, even while therapy is ongoing. Successful utilization of palliative care as soon as it is medically appropriate requires not only that physicians outside of the palliative care specialty receive training about its benefits but also that physicians learn to communicate better with patients about their choices for care during serious illness. To facilitate these goals, policymakers must amend relevant law to harmonize the payment systems for palliative and hospice care and to avoid perpetuating the artificial dichotomy between therapeutic, palliative, and hospice care. Even then, however, the obstacles to integration are substantial and entrenched.

5. See infra notes 49 to 78 and accompanying text.

6. There is a growing interest in the integration of the modifying influence of palliative care into the care and culture of the ICU. The IPAL-ICU project seeks to improve palliative care in the ICU by providing a central repository for exchanging evidence, expertise, and information. See IPAL-ICU PROJECT, CTR. TO ADVANCE PAlliative CARE, www.capc.org/ipal (last visited Nov. 7, 2017). Among other things, the project provides technical assistance with assessing institutional needs and competencies with respect to the provision of palliative care. See, e.g., Judith E. Nelson et al., Implementing ICU Screening Criteria for Unmet Palliative Care Needs: A Guide for ICU and Palliative Care Staff, IPAL-ICU (2013), https: / / media.capc.org/filer_public/80/be/80be3587-6ca1-4eb8-93f07fa0e30cd153/76_66_ipal-icu-implementing-icu-screening-criteria-for-unmetpalliative-care-needs.pdf.

7. See infra notes 164 to 182 and accompanying text. 


\section{Overutilization of Therapy and Life-Prolonging Care}

Medicare data clearly demonstrates that the United States spends substantial health care dollars in the last year and, especially, in the last weeks of life. Approximately one-third of medical expenses for the last year of life are spent in the final month, and high-intensity therapies and other interventions in that final month account for nearly $80 \%$ of these costs. ${ }^{.}$The latest numbers suggest that about $30 \%$ of Medicare patients spend time in an Intensive Care Unit (ICU) in the last thirty days of life or die in an ICU.' Many patients also receive aggressive interventions, such as cardiopulmonary resuscitation and ventilator support in acute care settings, even when near death. ${ }^{10}$ For cancer patients in particular, Medicare utilization data indicates that in the last month prior to death, patients received high levels of inpatient hospital care and that only $54 \%$ of these patients received any hospice care." By contrast, recent data suggest that hospice utilization for residents in nursing homes who do not have cancer has risen significantly between 2004 and 2009 and has resulted in lower utilization of various intensive interventions at the end of life. ${ }^{12}$ Utilization of

8. See Baohui Zhang et al., Health Care Costs in the Last Week of Life: Associations with End-of-Life Conversations, 169 ARCHIVES INTERNAL MED. 480, 482-84 (2009). Moreover, 30\% of Medicare dollars spent go to care for the 5\% of Medicare beneficiaries who die each year. See Amber E. Barnato et al., Trends in Inpatient Treatment Intensity Among Medicare Beneficiaries at the End of Life, 39 HEALTH SERV. RES. 363, 363-64 (2004).

9. Donald M. Berwick \& Andrew Hackbarth, Eliminating Waste in U.S. Health Care, 307 J. AM. MED. Ass'N 1513 (2012) (describing six categories of health care spending waste, including overtreatment such as use of surgery when watchful waiting is better and unwanted intensive care at the end of life and estimating that wasteful spending in the overtreatment category accounts form between $\$ 158$ billion and \$226 billion in 2011); see Teno, supra note 2, at 473 (noting that, in 2009, $29.2 \%$ of patients who died had received care in an ICU in the previous 30 days).

10. See Amresh Hanchate et al., Racial and Ethnic Differences in End-of-Life Costs: Why Do Minorities Cost More than Whites?, 169 ARCHIVES INTERNAL MED. 493, 497-98 (2009) (surveying use of expensive end of life interventions among a large sample of Medicare beneficiaries and finding patterns of substantial expenditure on life-sustaining treatment in the final six months of life).

11. See Nancy E. Morden et al., End-of-Life Care for Medicare Beneficiaries with Cancer Is Highly Intensive Overall and Varies Widely, 31 HEALTH AFF. 786, 789 (2012) (finding wide variations among different types of hospitals in rates of care that were not easily explained by expected variable such as for-profit status, size, or cancer center designation).

12. See Pedro Gonzalo et al., Changes in Medicare Costs with the Growth of Hospice Care in Nursing Homes, 372 NEW ENG. J. MED. 1823 (2015) (finding that hospice use for Medicare beneficiaries in nursing homes rose from $27.6 \%$ of residents in 2004 to $39.8 \%$ of residents in 2009) [hereinafter Gonzalo et al.]; see also Shannon Griffin et al., JAMA Infographic Visualizing Health Policy: Medicare and End-of-Life 
hospice care has been shown to reduce ICU admissions, tube feeding, and hospital transfers in the last three months of life. ${ }^{13}$ Nevertheless, the overall effect of increased hospice use has been to increase Medicare spending for the nursing home population, mainly because the growth of for-profit hospice providers has led to the enrollment in hospice of residents without cancer, whose life expectancy is more difficult to predict."

Despite this uptick in overall utilization of hospice care, concerns remain about care in the final month of life. Recent data suggest continuing concerns about pain management, management of dyspnea, and attention to anxiety, depression, and spiritual concerns during the last month of life..$^{15}$

At one level, this heavy spending at the end of life is unsurprising-it makes sense that many dying individuals will require substantially more medical care at this point in their lives than previously. The more challenging question is how much of this care is "appropriate" in the effort to prolong life and at what point should the focus turn from prolonging life to ensuring a "good death." The answer to this question, as with all complex questions, is "it depends." The usual measure for evaluating medically appropriate care is whether it comports with the individual patient's preferences ${ }_{1}^{16}$ although it is also ap-

Care, 316 J. AM. MED. ASSN. 1754 (2016) (illustrating an \$8.1 billion increase in Medicare spending overall between 2000 and 2014) [hereinafter Griffin et al.].

13. See Gonzalo et al., supra note 12, at 1828-29 (finding a 2.4 percentage point reduction in hospital transfers, a 1.2 percentage point reduction in tube-feeding, and a 7.1 percentage point reduction in ICU care).

14. See id. at 1829 (finding that this growth in for-profit enrollment, coupled with a per diem reimbursement rate for hospice care, has actually resulted in an average net increase of $\$ 6,761$ in Medicare payments per deceased resident between 2004 and 2009, despite the decreased utilization of intensive interventions); see also Kathy L. Cerminara, Hospice and Health Care Reform: Improving Care at the End of Life, 17 WIDENER L. REV. 443, 460-65 (2011) (detailing 128\% increase in number of for-profit hospices between 2001 and 2008) [hereinafter Cerminara]. The increase in number of for-profit hospices, combined with results of a Medicare Payment Advisory Commission report revealing that more than $84 \%$ of hospices exceeding the aggregate cap were for-profit, led to regulatory and Congressional concerns about fraud and abuse in the hospice industry.

15. See Joan M. Teno et al., Is Care for the Dying Improving in the United States?, 18 J. PALliative MED. 662, 664-65 (2015) (comparing data from surveys in 2000 with survey data in 2011-13 and finding that 25.2\% of respondents from the later dates reported unmet pain relief needs for their loved ones compared with $15.5 \%$ in 2000 and that later survey respondents also reported continuing high rates of unmet need for anxiety and depression and only a slight improvement in addressing dyspnea) [hereinafter Teno et al.].

16. See Canterbury v. Spence, 464 F.2d 772, 780 (D.C. Cir. 1972). See generally Daniel Brudney, Choosing for Another: Beyond Autonomy and Best Interests, 
propriate to consider the effects of medical care utilization on the patient's experience of dying and on the resources of the health care system. Although patient preferences regarding intensiveness of cancer care and end-of-life care vary widely, most patients prefer care that enhances comfort and allows them to remain at home during the final months, rather than inpatient therapeutic care at the very end of the illness. ${ }^{17}$

\section{A. The Benefits of Palliative and Hospice Care}

"Palliative care," in the purely clinical sense, refers to medical care intended to alleviate symptoms associated with illness, whatever the patient's prognosis. ${ }^{15}$ Depending on the individual patient's circumstances, this type of care may address pain, shortness of breath, insomnia, depression, nausea, and lack of appetite, among other symptoms. ${ }^{19}$ Palliative care is appropriate for a broad array of illnesses and conditions including both chronic and terminal illness.

The broader meaning of palliative care is more interdisciplinary, however, and focuses on quality of life. Key principles of palliative care include not only physical symptom management, but also increased attention to the whole patient, open and honest communication, and attempts to set medically appropriate goals. ${ }^{20}$ Palliative care

HASTINGS CTR. REP. 31 (March/April 2009) (discussing differences among concepts of autonomy, self-determination and authenticity).

17. See Gonzalo et al., supra note 12, at 792 (summarizing the results of multiple studies on this question).

18. InSt. OF MeD. COMMITTEE ON APPROACHING DeAtH: AdDRESSING KeY END OF LIFE ISSUES, Dying in America: Improving Quality and Honoring Individual Preferences Near the End of Life 2-11 (2015), http://www.nationalacademies. org / hmd / Reports / 2014 / Dying-In-America-Improving-Quality-and-HonoringIndividual-Preferences-Near-the-End-of-Life.aspx [hereinafter DYING IN AMERICA].

19. Lise M. Stevens, Palliative Care, 296 J. AM. MED. ASSN. 1428, 1428 (2006). See Amy S. Kelley \& Diane E. Meier, Palliative Care - A Shifting Paradigm, 363 NEW ENG. J. MED. 781, 781-82 (2010) ("Palliative care is often appropriate even while the patient is receiving therapeutic care; the two are not mutually exclusive. Once therapeutic care is discontinued, palliative care continues in order to manage symptoms. Non-hospice palliative care is offered simultaneously with lifeprolonging and curative therapies for persons living with serious, complex, and life-threatening illness.").

20. DYING IN AMERICA, supra note 18, at 2-11-2-13; see Thomas J. Smith et al., American Society of Clinical Oncology Provisional Clinical Opinion: The Integration of Palliative Care into Standard Oncology Care, 30 J. CliniCAL OnCOLOGY 880, 882 (2012) [hereinafter T. Smith]; see also Amy S. Kelley \& R. Sean Morrison, Palliative Care for the Seriously Ill, 373 NEW ENG. J. MED. 747, 747 (2015) (explaining that palliative care can also include services from medicine, social work, chaplaincy, and 
team consultations thus can also incorporate "decision support" for patients and families, including assistance with advance directive completion and help with clarifying reasonable goals of care and choosing among options with a better understanding of risks and benefits. ${ }^{21}$ In addition, it is important to distinguish palliative care from end-of-life care, particularly hospice care. Although the two types of care naturally intersect for terminally ill patients, palliative care is a broader concept that is distinct from and ideally should be implemented well before end-of-life care.22

Although access to palliative care services in the United States is improving, many hospitals still lack palliative care programs. The latest research shows that $67 \%$ of hospitals with fifty or more beds have a palliative care program and that $90 \%$ of hospitals with 300 or more beds have such a program. ${ }^{23}$ In addition, palliative care programs are more prevalent in some regions of the country, such as the Northeast, than in others, leading to overall inadequate access to palliative care in certain places. ${ }^{24}$ Finally, there is a documented shortage of palliative care specialists overall, which creates an additional hurdle to access for many patients. ${ }^{25}$

"Hospice" refers to care provided at the end of life and includes palliation of physical symptoms along with psychological, spiritual, and family support through an integrated team of professionals. ${ }^{26}$

others in order to improve the quality of life of seriously ill patients) [hereinafter Kelley \& Morrison].

21. See Bethel Ann Powers et al., Meaning and Practice of Palliative Care for Hospitalized Older Adults with Life Limiting Illnesses, 2011 J. AGING RESEARCH 4 (2011) [hereinafter Powers].

22. Id. at 1 (discussing the distinctions between and intersection of palliative care and end-of-life care and recommending better training of health care providers to understand that "end of life" is not a "well-demarcated period of time before death."); see also Cerminara, supra note 14, at 455-58 (advocating coverage of concurrent, or open-access, hospice care).

23. See Tamara Dumanovsky et al., The Growth of Palliative Care in U.S. Hospitals: A Status Report, 19 J. PALLIATIVE MED. 8, 10-12 (2016) (adding that non-profit and public hospitals were more significantly likely than for-profit hospitals to have palliative care programs) [hereinafter Dumanovsky et al.].

24. Id. at 12

25. See Kelley \& Morrison, supra note 20, at 752 (noting also that the Affordable Care Act has increased demand for palliative care specialists by offering incentives to expand palliative care); see also Dale Lupu Estimate of Current Hospice and Palliative Medicine Physician Workforce Shortage, 40 J. PAIN SYMPTOM MGMT. 899, 905-07 (2010) (concluding that the estimated gap between supply of and demand for palliative care specialists probably requires an additional 6,000 to 18,000 individuals to enter the field).

26. Kathy L. Cerminara, Pandora's Dismay: Eliminating Coverage-Related Barriers to Hospice Care, 11 FLA. COASTAL L. REV. 107, 113-14 (2010). 
Hospice care prioritizes the management of symptoms (such as pain, depression, or difficulty breathing) over the treatment of the disease itself. ${ }^{27}$ Hospice may include in-home care by trained nurses and physicians or inpatient care at a specialized facility or skilled nursing facility, as well as support for the patient's family through respite services, counseling, and grief counseling. ${ }^{25}$ Hospice by definition is a subset of and includes palliative care, but palliative care does not necessarily require that a patient enter a hospice program or even that the patient be terminally ill. ${ }^{29}$

Providing access to good palliative care as soon as it is medically appropriate is essential to improving patient outcomes and avoiding distressing symptoms. In fact, a growing body of evidence demonstrates that an emphasis on palliative care, in conjunction with carefully considered therapeutic care, can improve patients' quality of life and even prolong survival. ${ }^{30}$ At the same time, more therapeutic and life-prolonging interventions at the end of life are associated with poorer outcomes. ${ }^{3 n}$

More specifically, a number of recent studies suggest that delays in implementation of palliative care or the involvement of a palliative specialist, immediately upon commencement of invasive and debilitating treatment, results in poorer quality of life for patients and more use of invasive care at the end of life. One study of patients with met-

27. Id. at $114-15$.

28. See Brian Pace, Hospice Care, 295 J. AM. MED. ASSN. 712, 712 (2006) (providing consumer-oriented information about hospice care and its goals and values); see generally Perez \& Cerminara, supra note 3 (detailing regulatory conditions of participation for hospices).

29. Ravi B. Parikh et al., Early Specialty Palliative Care-Translating Data in Oncology into Practice, 369 N. ENG. J. MED. 2347, 2347 (2013) (warning that "[l]imiting specialty palliative care to those enrolled in hospice or admitted to the hospital ignores the majority of patients facing a serious illness, such as advanced cancer, who have physical and psychological symptoms throughout their disease") [hereinafter Parikh et al.].

30. See T. Smith, supra note 20 , at 880 (“While a survival benefit from early involvement of palliative care has not yet been demonstrated in other oncology settings, substantial evidence demonstrates that palliative care-when combined with standard cancer care or as the main focus of care-leads to better patient and caregiver outcomes. These include improvement in symptoms, QOL, and patient satisfaction, with reduced caregiver burden. Earlier involvement of palliative care also leads to more appropriate referral to and use of hospice, and reduced use of futile intensive care.").

31. See Matthijs Kox \& Peter Pickkers, "Less Is More" in Critically Ill Patients: Not too Intensive, 173 JAMA INTERNAL MED. 1369, 1369 (2013) (concluding, based on a meta-analysis of multiple clinical trials, that many common treatments for critically ill patients pose a high risk of iatrogenic harm compared with their potential benefit and ought to be used more cautiously). 
astatic non-small-cell lung cancer found that patients who received palliative care very early in the treatment process lived significantly longer and reported better mood and quality of life than the control group who received only standard therapy..2 The same study also suggested that the combination of palliative with standard oncology care "may facilitate the optimal and appropriate administration of anticancer therapy, especially during the final months of life." ${ }^{\prime 3}$

Other studies add weight to the case for early introduction of palliative care. For example, another study of cancer patients found that palliative care that commenced more than ninety days before death resulted in lower rates of inpatient hospitalization, ICU, and emergency department utilization compared with late referrals to palliative care. ${ }^{34}$ In another study of patients with various forms of advanced cancer, patients who received early palliative care as outpatients reported no difference in quality of life at three months based on one scale (compared with patients who received routine cancer care), but reported significantly improved quality of life and satisfaction with care on other scales..$^{35}$ By four months out, the palliative care group reported significant differences on all but one of the measures used, suggesting that early palliative care intervention provides real benefits. ${ }^{36}$ Based on these and other studies, the American Society of Clinical Oncology has issued a provisional clinical opinion recom-

32. See Jennifer S. Temel et al., Early Palliative Care for Patients with Metastatic Non-Small-Cell Lung Cancer, 363 NEW ENG. J. MED. 733, 736-38 (2010) (finding that patients recently diagnosed with lung cancer who began receiving palliative care immediately lived an average of almost three months longer than patients who received standard therapeutic treatment only) [hereinafter Temel].

33. Id. at 739-40 (adding that "[e]arly introduction of palliative care also led to less aggressive end-of-life care, including reduced chemotherapy and longer hospice care").

34. See J. Brian Cassel et al., Does Palliative Care Reduce ICU Length of Stay?, 13 J. PALLIATIVE MED. 761, 761-67 (finding, in a meta-analysis of 12 studies, that PC intervention significantly reduces ICU utilization); see also Colin Scibetta et al., The Costs of Waiting: Implications of the Timing of Palliative Care Consultation Among a Cohort of Decedents at a Comprehensive Cancer Center, 19 J. PALLIATIVE MED. 69, 69-70 (2016).

35. See Marie Bakitas et al., Effects of Palliative Care Intervention on Clinical Outcomes in Patients with Advanced Cancer: the Project ENABLE II Randomized Controlled Trial, 302 J. AM. MED. ASSN. 741, 742-48 (2009) (finding that patients assigned to usual cancer care plus a nursing intervention that included weekly educational sessions and follow-up reported significantly higher quality of life, lower symptom intensity, and reduced depression compared with patients who received only standard cancer care) [hereinafter Effects of Palliative Care Intervention]; see also Camilla Zimmerman et al., Early Palliative Care for Patients with Advanced Cancer: Cluster-Randomized Controlled Trial, 383 LANCET 1721, 1727 (2014).

36. See Effects of Palliative Care Intervention, supra note 35, at 742-48. 
mending that patients with non-small-cell lung cancer receive palliative care immediately with the initial treatments and that palliative care combined with standard cancer care should be considered early in the treatment of any patient with metastatic cancer. ${ }^{37}$ Related research also makes a strong case that, for certain types of cancers, early introduction of hospice care prolongs survival. ${ }^{3 \mathrm{~s}}$

The benefits of early palliative care extend beyond cancer patients. In a recent study of patients suffering from breathlessness as a symptom of various advanced diseases, patients assigned to a support service group that provided symptom palliation combined with physical therapy and breathlessness management techniques reported improved control over their symptoms and survived longer than the control group. ${ }^{39}$ In another study of seriously ill patients with cancer, emphysema, or congestive heart failure, dyspnea improved among those patients who were randomly assigned to usual care plus comprehensive care from a palliative care team. ${ }^{40}$ In addition, their spiritu-

37. See Thomas J. Smith et al., American Society of Clinical Oncology Provisional Clinical Opinion: The Integration of Palliative Care into Standard Oncology Care, $30 \mathrm{~J}$. CLINICAL ONCOLOGY 880, 881 (2012) (adding that "[s]trategies to optimize concurrent palliative care and standard oncology care, with evaluation of its impact on important patient and caregiver outcomes . . . and on society, should be an area of intense research"); see also Copy of QCPI Measures and Reporting Pathways - Fall 2016 for Public Website, AM. SOC'Y OF CLINICAL ONCOLOGY INST. FOR QUALITY, http:/ / www.instituteforquality.org/files / copy-qopi-measures-and-reportingpathways-fall-16-public-websitexlsx (detailing measures requiring attention to palliative care and hospice in the Care at the End of Life section).

38. See Stephen R. Connor et al., Comparing Hospice and Nonhospice Patient Survival Among Patients Who Die Within a Three-Year Window, 33 J. PAIN SYMPTOM MGMT. 238, 241-42 (2007) (finding that all patient cohorts who received hospice care survived an average of eight days longer than those who did not and that patients with lung (279 versus 240 days) and pancreatic (210 versus 189 days) cancer, as well as patients with congestive heart failure (402 versus 321 days), who received hospice care survived significantly longer); see also Akiko M. Saito et al., Hospice Care and Survival Among Elderly Patients with Lung Cancer, 14 J. PALLIATIVE MED. 929, 935-36 (2011) (finding that, among Medicare beneficiaries with nonsmall cell lung cancer, hospice care did not shorten life and that patients with a longer length of hospice care survived longer than those who received short-term hospice care only).

39. See Irene J. Higginson et al., An Integrated Palliative and Respiratory Care Service for Patients with Advanced Disease and Refractory Breathlessness: A Randomised Controlled Trial, 2 LANCET RESPIRATORY MED. 979, 982-85 (2014) (noting that the increased survival effect was not found for patients with cancer but was significant for patients with other diseases including COPD and interstitial lung disease).

40. See Michael W. Rabow et al., The Comprehensive Care Team: A Controlled Trial of Outpatient Palliative Medicine Consultation, 164 ARCHIVES INTERNAL MED. 83, 83-85 (2004) (explaining that the palliative care team included a social worker, nurse, chaplain, pharmacist, psychologist, and other non-physician professionals, along with three physicians) [hereinafter Rabow et al.]. 
al well-being was reported as better than the standard care group, and more of the intervention group completed advance directives." There was no reported difference in pain, anxiety, or depression, or in utilization of the emergency department, hospitalization, or site of death..$^{2}$ Another similar study of outpatients reported greater patient satisfaction among the palliative care group, along with lower total average health care costs, higher advance directive completion, and longer hospice stays..$^{43}$ All of these measures indicate that early integration of palliative care on an inpatient or outpatient basis can improve patient satisfaction and mood, and can lead to lower rates of acute care utilization and hospitalization, and reduced costs. To the extent that this less intensive approach to care at the end of life comports with individual patients' goals and preferences, increased palliative care use for patients receiving therapeutic care has the potential to benefit patients, families, and payors.

The distinction between palliative and hospice care is artificial when the goal is to provide palliation of symptoms and psychological supportive care for patients (and families) throughout the entire course of terminal illness. It is important to avoid treating palliative care as something that one implements only when cure is unattainable. Instead, the goal should be to encourage physicians who are providing treatment to consult and include palliative care specialists in the care plan from the outset.

There are, however, several obstacles to the achievement of this goal. Part of the problem arises from poor communication between physicians and patients and poor underlying understanding on the part of physicians about what palliative care is and when it is appropriate." Many physicians themselves misunderstand the idea behind palliative care and thus are understandably reluctant to initiate a discussion of palliative care with patients who are beginning or in the middle of an invasive and debilitating therapeutic regimen..$^{45}$ They also do not understand because they have not been appropriately trained in how to discuss advance care planning with patients." Separately, as explained more fully below, payment systems create an artificial di-

41. Id.

42. See id. at $85-89$.

43. See Glenn Gade et al., Impact of an Inpatient Palliative Care Team: A Randomized Controlled Trial, 11 J. PALLIATIVE MED. 180, 181-90 (2008).

44. See infra notes 50, 103 to 108 , and accompanying text.

45. See infra notes 120 to 126 and accompanying text.

46. See Griffin et al., supra note 12 , at 1754 . 
chotomy between palliative and hospice care. ${ }^{47}$ Most insurance, including Medicare, requires patients to cease active therapy in order to become eligible for coverage of hospice, ${ }^{48}$ a decision that some patients may resist because it represents relinquishing hope for a cure. For these reasons, within the continuum of care for terminally ill patients, when to initiate palliative care and when to transition to hospice pose conundrums, particularly when patients are not well-informed about their prognosis and their options.

\section{B. The Artificial Payment Distinction Between Palliative and Hospice Care}

It is difficult to overstate the complexity of coding, billing, and payment for health care services in the United States. The interplay of health care providers and payors inspires frustration among providers, ${ }^{49}$ who subconsciously may tailor treatment decisions to avoid or minimize frustration with reimbursement processes. ${ }^{50}$ In addition, traditional payment/coverage rules, inspired by Medicare," erect barriers to appropriate utilization of palliative and hospice care. There is great room for improvement in the overall payment method for therapeutic and palliative care on one hand and hospice care on the other. Even

47. See infra notes 50 to 95 and accompanying text.

48. See Kathy L. Cerminara, Pandora's Dismay: Eliminating Coverage-Related Barriers to Hospice Care, 11 FlA. COASTAL L. REV. 107, 145 n.200 (2010) [hereinafter Cerminara II].

49. See, e.g., David A. Hanauer et al., Two-Year Longitudinal Study Assessment of Physicians' Perceptions After Replacement of a Longstanding Homegrown Electronic Health Record: Does a J-Curve of Satisfaction Really Exist?, 23 J. AM. MED. INFORMATICS ASSN. 1093 (2016) (reporting frustration and dissatisfaction among physicians two years after switching from one electronic health record system to another); Seung Jun Lee et al., Seeing the Forest for the Trees: Institutional Environment Impacts on Reimbursement Processes and Healthcare Operations, 47-48 J. OPERATIONS MGMT. 71, 72 ("Healthcare administrators and policy makers tout reimbursement processes as salient causes of wasteful expenditures and poor operational performance.") [hereinafter Lee et al.].

50. See Lee et al., supra note 49 , at 76 (concluding that "[r]eimbursement processes can both enable and impede care delivery across different regions and populations").

51. Id. at 72 ("As in any multi-trillion dollar industry, healthcare providers must conform their processes to the regulations and policies of institutions having power over the providers in both care provision and reimbursement." All or virtually all of those institutions use billing codes developed by the federal government.); see Haiden A. Huskamp et al., Providing Care at the End of Life: Do Medicare Rules Impede Good Care? A Study of End-of-Life Care Providers Reveals Some Shortcomings, 20 HEALTH AFF. 204, 209 (2001) ("In the six markets studied, . . . coverage of and eligibility for end-of-life services were similar in most commercial health plans and [fee-for-service] Medicare."). 
once a patient on the path toward death has begun to accept the endpoint, traditional payment rules require what the patient may perceive as premature renunciation of all hope of recovery before hospice care will be covered.

First, incorporation of palliative care into a treatment plan concurrently with curative measures poses financial questions for a health care institution. A hospital or other facility must begin with generally applicable questions of profitability, just as it must with any other line of business. ${ }^{52}$ A palliative care perspective, generally speaking, advocates a "less is more" approach to late-stage, high-intensity treatments, focusing on quality of life instead of extent of life remaining. ${ }^{53}$ In a fee-for-service setting, such lower-intensity care generally will result in less billing, and thus less payment generated. ${ }^{54}$ While palliative care services also reduce costs, it may be difficult to recognize and illustrate the cost reductions when determining profitability lineby-line. ${ }^{.5}$ In other words, palliative care initially may create concerns among facility administrators because it reduces reimbursements; they will fully recognize the benefits of palliative care only after also analyzing the cost reductions attributable to it.

Furthermore, even if committed to providing palliative care, an institution will face many challenges in billing for it. In 2015, the Centers for Medicare and Medicaid Services (CMS) resolved one of those challenges by approving two billing codes for advance care planning. ${ }^{56}$

52. See Bruce Jennings \& Mary Beth Morrissey, Health Care Costs in End-of-Life and Palliative Care: The Quest for Ethical Reform, 7 J. SOCIAL WORK IN END-OF-LIFE \& PALLIATIVE CARE 300, 311 (2011) ("Facilities like large hospitals often make resource allocation decisions by determining what service areas to maintain and to invest in.") [hereinafter Jennings \& Morrissey]; see generally NAT'L ASS'N HOME CARE \& HOSPICE \& HOME CARE \& HOSPICE FIn. MANAGERS ASS'N, Palliative Care White Paper (June 24, 2015), https:// www.nahc.org/assets/1/7/NAHCPC WhitePaper.pdf (describing the business and clinical considerations associated with incorporating palliative care services into a health care facility's operation) [hereinafter NAHC].

53. J. Brian Cassel et al., The Business Case for Palliative Care: Translating Research Into Program Development in the U.S., 50 J. PAIN \& SYMPTOM MGT. 741, 742 (2015) (expanding on this "misalignment between clinical and financial interests") [hereinafter Cassel et al.].

54. Id.

55. Id. This would not apply to value-based payment systems pursuant to which CMS pays for quality rather than quantity of care. Id. at 744 (noting that palliative care "has always been associated with quality" and quality measures are increasingly taking account of overutilization of services such as ICU admission and underutilization of services such as hospice and palliative care).

56. AAFP, Advance Care Planning, http://www.aafp.org/practicemanagement/payment/coding/acp.html (last visited Nov. 7, 2017) [hereinafter Advance Care Planning]. 
"Advance care planning" encompasses in-person discussions between or among physicians or other qualified health care professionals, the patient, family member(s), and surrogate, if appropriate, "about the care [the patient] would want to receive if ... unable to speak for [him or herself,] including the explanation and discussion of advance directives such as standard forms (with completion of such forms, when performed)." ${ }^{\prime 57}$ CMS thus responded to numerous calls for financial recognition of the benefits of such documentation-related counseling. ${ }^{.8}$ But challenges still remain for institutions attempting to determine how to bill and be reimbursed for non-hospice palliative care. ${ }^{59}$ For example, outside of hospice care, an institution operating on a fee-forservice model cannot bill for chaplain or social worker services, ${ }^{60}$ yet palliative care depends on interdisciplinary teamwork from these and other professionals.

Individual physicians face similar challenges. On the bright side, they may use CMS's billing codes to be paid for advance care planning" and they may "bill and be reimbursed for palliative care services and consultations under Part $\mathrm{B}^{\prime \prime \prime}{ }^{\prime 2}$ as may nurse-practitioners and licensed clinic social workers. ${ }^{63}$ In the ideal setting, however, in which therapeutic measures and palliative care are provided concurrently, the associated complexity of required documentation may chill the

57. National Hospice and Palliative Care Organization, The Medicare Hospice Benefit, Regulations, Quality Reporting, and Public Policy, HOSPICE POLICY COMPENDIUM 28 (Jan. 4, 2016).

58. See Kathy L. Cerminara, Eliciting Patient Preferences in Today's Health Care System, 4 PSYCHOL. PUB. POL'Y \& LAW 688, 698 (1998) (stating that "Medicare and other billing codes should clearly include categories for . . . advance directive planning"); Jennings \& Morrissey, supra note 52, at 307 (recommending establishment of "appropriate reimbursement and financing mechanisms for hospitalbased palliative care consultation and services"); Parikh et al., supra note 29, at 2350 (deeming Medicare reimbursement "necessary to encourage and reinforce early palliative care"); Teno et al., supra note 15, at 665 (explaining that "current financial incentives under Medicare reward procedures reward procedures and ICU utilization, but do not incentivize these in-depth discussions").

59. Jennings \& Morrissey, supra note 52, at 305 (lamenting the absence of a "clearly defined public policy and financing mechanism for palliative care services that are not provided by a certified hospice and not covered by the [Medicare] hospice benefit"). At least, however, unlike advance care planning until recently, there exist billing codes for hospital-based palliative care. For a history of the creation of and initial difficulties surrounding the hospital-based palliative care billing codes, see Carol F. Capello et al., Payment Code for Hospital-Based Palliative Care: Help or Hindrance?, 1 J. PALLIATIVE MED. 155 (1998).

60. Cassel et al., supra note 53, at 745.

61. See Advance Care Planning, supra note 56 (noting that both Part A and Part $B$ cover advance care planning under the new billing codes).

62. Jennings \& Morrissey, supra note 52, at 305.

63. NAHC, supra note 52, at 20. 
willingness to bill for (and thus perhaps provide) palliative care. Literature indicates that medical professionals are beginning to consider and study the incorporation of palliative care in such diverse settings as the ICU ${ }^{\omega 4}$ and the Emergency Department (ED). ${ }^{65}$ In 2012, the medical journal CHEST devoted an entire five pages to an article instructing physicians and coders in the complex art of coding for the provision of palliative care in the ICU. ${ }^{6}$ In the ED, physicians have expressed concern about lack of documentation from the patient's primary care physician that would appropriately enable them to engage in palliative care consultation. Increased primary care documentation of advance care planning conversations presumably would assist by enabling more ED-provided palliative care consultation, ${ }_{, 5}^{\text {ss }}$ but until recently the time taken to complete that documentation was not billable. ${ }^{9}$ To the extent that such documentation could be expected to occur now that CMS has authorized billing codes for those conversations, one unanticipated result may be greater physician willingness to provide palliative care in the ED. Nevertheless, other barriers remain: lack of knowledge about palliative care, complex coding, the perception that ED physicians and palliative care physicians play very different roles in medicine, lack of patient-specific information, and lack of time, among others.

Outpatient palliative care services ${ }^{70}$ also are effective and may facilitate early access, but the outpatient setting erects even more barriers to reimbursement for the services of non-physician providers than exist in the inpatient setting. ${ }^{12}$ Sometimes called community-based palliative care, ${ }^{2}$ outpatient palliative care has been demonstrated to be

64. E.g., Dana R. Lustbader et al., Physician Reimbursement for Critical Care Services Integrating Palliative Care for Patients Who are Critically Ill, 141 CHEST 787 (2012) [hereinafter Lustbader et al.].

65. E.g., Alexander K. Smith et al., Am I Doing the Right Thing? Provider Perspectives on Improving Palliative Care in the Emergency Department, 54 ANNALS OF EMERGENCY MED. 86 (2009) [hereinafter A. Smith].

66. Lustbader et al., supra note 64.

67. A. Smith, supra note 65 , at 92.

68. Id.

69. See supra notes 56 to 58 (discussing recent approval of payment codes for advance care planning).

70. These are palliative care services provided when the patient is neither hospitalized nor under hospice care. See Cassel et al., supra note 53, at 744 (noting that "[h]ospice care is being used very close to the time of death, and inpatient [palliative care] can only be provided once patients are hospitalized").

71. See Lustbader et al., supra note 64 , at 788 (discussing the difficulties that arise for this billing in the inpatient setting).

72. See Cassel et al., supra note 53, at 744 . 
effective at increasing patient comfort and quality of life and avoiding unnecessary hospitalizations, at least among cancer patients..$^{35}$ Yet, as noted previously, ${ }^{74}$ palliative care is a quintessentially team-based endeavor, requiring numerous professionals ranging from nurses to social workers to chaplains..$^{75}$ Again, as with advance care planning, policymakers should examine payment policy to account for this hidden expense. Hospitals may be able recoup some of those costs by institutionally billing for inpatient care, ${ }^{76}$ but that option is not available in the outpatient setting. Nor can those professionals bill directly for their roles in providing palliative care, ${ }^{n}$ although home health services can bill for nursing, social work, and spiritual care to some extent."

Finally, reimbursement obstacles are not eliminated once a patient qualifies for hospice care, even though Medicare has a hospice benefit and it is a per-diem rate meant to capture all costs of not only medical professionals, but also the rest of the interdisciplinary team. Medicare currently pays for hospice services only if a terminally ill individual foregoes payment for certain other medical services: those "related to the treatment of the terminal condition for which hospice care was elected or a related condition." ${ }^{\prime \prime}$ In other words, patients must forego coverage of curative care to receive coverage of hospice care.

The distinction between care intended to cure a terminal condition and care intended as palliation is less straightforward than it might appear. Certainly CMS intends that Medicare will pay for treatment of a terminally ill cancer patient's broken leg even if also paying hospice benefits. ${ }^{s 0}$ More confusingly, however, a patient who is terminally ill with end-stage renal disease (ESRD) must forego Medicare payment for dialysis for Medicare to fund hospice services. ${ }^{81}$ If, however, that patient is terminally ill with another disease, Medicare will pay for the dialysis, while also funding hospice services and re-

73. See Parikh et al., supra note 29, at 2347-49 (summarizing studies).

74. See Cassel et al., supra note 53, at 745.

75. Id. at 747 .

76. Id.

77. $I d$.

78. Id.

79. 42 C.F.R. $\S \S 418.3,418.24(\mathrm{~d})(2)$ (2018); see also JUDITH A. STEIN \& ALFRED J. CHIPLIN, JR., 2009 MEDICARE HANDBOOK 5-5 (2009).

80. Cerminara II, supra note 48 , at 130 .

81. Id. 
quiring waiver of benefits for treatment of the terminal illness. ${ }^{82}$ Moreover, some treatments can be either curative or palliative, depending on context. Physicians may use chemotherapy and radiation to attack a disease, but both can be used to ease pain and other symptoms. ${ }^{83}$

This false dichotomy impacts both providers and patients considering whether hospice care is appropriate. In one striking study, researchers investigated levels of knowledge about Medicare payment among registered nurses, nurse managers, and social workers. ${ }^{84}$ They sought to determine whether and to what extent these professionals understood the ability to receive Medicare reimbursement for both dialysis treatment and hospice services when the patient was terminally ill due to something other than ESRD. ${ }^{.5}$ The researchers concluded: "Confusion exists when evaluating a patient with ESRD for hospice services.... Hospice organizations interpret Medicare regulations differently, making discontinuation of dialysis conditional in some programs, while not a condition in others." ${ }^{\prime \prime 6}$ Such confusion can negatively influence not only the advice patients receive, but also the timing of referrals to hospice.

The requirement that a patient forego curative treatment for the terminal condition to obtain hospice benefits also inhibits patient comfort. First, it may preclude relief of symptoms associated with the curative treatment. ${ }^{.7}$ Second, renouncing curative treatment requires accepting impending death, and patient reluctance to do so can postpone initial election of Medicare-funded hospice care..$^{88}$ Additionally, "[d]ue to a variety of cultural influences, some Hispanic and African-American patients may never be willing to renounce curative care, even after they have accepted impending death." ${ }^{\prime s 9}$ In sum, the

82. Kimberly F. Thompson et al., Hospice and ESRD: Knowledge Deficits and Underutilization of Program Benefits, 35 NePHROLOGY NURSING J. 461, 463-64 (2008) [hereinafter Thompson et al.].

83. See Sarah Elizabeth Harrington \& Thomas J. Smith, The Role of Chemotherapy at the End of Life: "When Is Enough, Enough?," 299 JAMA 2667, 2669 (2008); Alexi A. Wright \& Ingrid T. Katz, Letting Go of the Rope-Aggressive Treatment, Hospice Care, and Open Access, 357 NEW ENG. J. MED. 324, 325 (2007).

84. See Thompson et al., supra note 82 , at 462-63.

85. Id.

86. Id. at 465 .

87. Cf. Powers, supra note 21 (noting that " $[\mathrm{t}]$ he requirement to cease active therapy in order to qualify for Medicare hospice benefits may be a relief for cancer patients but not necessarily so for patients with other diseases for which disease therapy may also bring relief of symptoms").

88. See Cerminara, supra note 14, at 450; Noah, supra note 3, at 352.

89. Cerminara, supra note 14 , at 450 . 
currently existing false payment dichotomy between therapeutic and palliative care on one hand and hospice care on another serves as an obstacle on the path toward high-quality, culturally competent endof-life care.

\section{Facilitating the Integration of Palliative and Therapeutic Care and Optimizing the Transition to Hospice Care}

Recent efforts to develop patient-centered care for people with advanced illness promise improvement in the experience of dying, at least in theory. But the implementation of these efforts will require a complex and multi-factorial approach that includes training of health professionals, reform of payment structures and "siloed" care delivery models, and the willingness of physicians, patients, and families to participate. ${ }^{\circ 0}$ Plenty of evidence illustrates the benefits of early and integrated palliative care and well-timed hospice care within the healthcare system as it currently operates. But achieving optimal endof-life care will require a complex set of reforms across many layers of our healthcare system in order to implement the needed changes." Three of the most significant are improving communication with patients and families, working interdisciplinarily with a variety of professionals to care for the whole patient, and eliminating the false payment dichotomy.

90. See DYING IN AMERICA, supra note 18, at S-8 (recommending insurer and provider practice changes designed to ensure coverage of "the provision of comprehensive care for individuals with advanced serious illness who are nearing the end of life").

91. See Laura P. Gelfman \& Diane E. Meier, Making the Case for Palliative Care: An Opportunity for Health Care Reform, 8 J. HEALTH \& BIOMEDICAL L. 57, 76-80 (2012) (describing various PC settings and reviewing broadly the necessary categories of reform, including training PC professionals, funding research into the benefits and optimization of PC, and improving access to PC including changing and improving the reimbursement methods for this type of care). 


\section{A. Early and Truthful Communication with Patients and Families}

Improved education, both in medical school and as part of continuing education, about effective patient communication can foster participatory decision-making and meaningful conversation between physicians and seriously ill patients and their families.9. however, a variety of obstacles to physicians and patients discussing care at the end of life. As a culture, we have embraced the idea that it is acceptable, even desirable, to take extreme measures to delay death." The desire of physicians, patients, and families to "do everything possible" comports with and perpetuates the belief that maximal utilization of life-prolonging measures and high-intensity therapies constitutes "the best" health care. Although attitudes among health care providers are shifting, not long ago it was common to interpret good care as demanding every available, medically relevant treatment..$^{95}$ Even as more commentators argue against the presumption in favor of utilizing medical technology simply because it is available, ${ }^{96}$ the evidence suggests that a systemic overutilization of

92. See generally Barbara A. Noah \& Neal R. Feigenson, Avoiding Overtreatment at the End of Life: Physician-Patient Communication and Truly Informed Consent, 36 PACE L. REV. 101 (2016).

93. See id. at 141-49 (describing and discussing the promises and limitations of physician training to improve communication with patients about end-of-life decisions); see also Dale G. Larson \& Daniel R. Tobin, End-of-Life Conversations: Evolving Practice and Theory, 284 JAMA 1573, 1577 (2000).

94. See Daniel Callahan, SetTing Limits: Medical Goals in an Aging SOCIETY 17 (Simon \& Schuster eds., 1987) ("Not only has health been transformed as a medical goal and social ideal, but the place of good health in individual lives . . . has moved from the sphere of the accidental and fortuitous-where death was once the companion of all age groups, beyond the help of medicine, politics, and economics- to the realms of high science and established psychological and political expectation. The technological imperatives that transformed the nature of medicine from caring to curing have no less profoundly affected our idea of health, moving it from a nebulous hope to a fundamental human and social requirement. What can be done medically ought to be done. What ought to be done ought to be available to all. What ought to be available to all becomes the moral responsibility of all."); Albert R. Jonsen, The God Squad and the Origins of Transplantation Ethics and Policy, 35 J. L. MED. \& ETHICS 238, 239-40 (2007) (noting society's reluctance to accept mortality).

95. See Barbara A. Noah, In Denial: The Role of Law in Preparing for Death, 21 ELDER L. J. 1, 27-28 (2013) (describing cultural and physician attitudes that sustain the medical technology juggernaut in caring for dying patients).

96. See DANiel CALlahan, TAMING THE Beloved BeAst: How MedicAL TeChNOlogy Costs ARe Destroying Our Health CARE SYSTEM 152, 152-55 (2009) (noting Daniel Callahan has so ably argued, medical research should focus on reducing morbidity in the final years of life and assuring that people receive excellent care as they die in order to reduce suffering. "Death itself, part of our biological nature, ought not to be seen as the primary target for health care, particularly when most of us now have the chance to live a full life" and observing that, 
medical treatments at the end of life persists for the majority of patients.

End-of-life communication poses serious challenges to physicians, many of whom struggle with feelings of failure when they cannot provide a cure." Many oncologists, as well as other physicians, lack training in how to have difficult conversations with seriously ill patients and their families." Because physicians can find conversations with seriously ill patients challenging, either due to lack of training or individual temperament, they are likely to avoid the conversations altogether or resort to non-specific statements about patient prognosis and the potential utility of additional treatment. Many physicians avoid or postpone disclosing details about patients' prognoses or spontaneously initiating discussions about ending therapeutic care and making the transition to hospice." Physicians also tend to be un-

paradoxically, as our society has become healthier, people have begun to worry more about health and to spend more technological resources on maintaining it); see also ATUL GAWANDE, BEING MORTAL: MEDICINE AND WHAT MATTERS IN THE END 155 (2014) ("People with serious illness have priorities besides simply prolonging their lives.... Our system of technological medical care has utterly failed to meet these needs, and the cost of this failure is measured in far more than dollars.") [hereinafter GAWANDE]; James F. Fries, Aging, Natural Death, and the Compression of Morbidity, 303 NEW ENG. J. MED. 130, 130 (1980) (discussing the common goal of shortening or avoiding, the period of "old age" as much as possible by preserving qualities that society generally associates with youth).

97. See Diane E. Meier et al., The Inner Life of Physicians and Care of the Seriously Ill, 286 JAMA 3007, 3007 (2001) (discussing the emotional response of physicians who treat patients will serious illnesses); see also Richard S. Kane, The Defeat of Aging Versus the Importance of Death, 44 J. AM. GERIATRICS SOC'Y 321, 322 (1996) (explaining that many physicians face challenges during end-of-life care because discussions of death are considered to be taboo).

98. See Nathan I. Cherny \& Raphael Catane, Attitudes of Medical Oncologists Toward Palliative Care for Patients With Advanced and Incurable Cancer, 98 CANCER 2502, 2508 (2003) (finding that a "substantial $42 \%$ of respondents reported that they had not received adequate training in palliative care during their residency training"); Judith E. Nelson et al., End-of-Life Care for the Critically Ill: A National Intensive Care Unit Survey, 34 CRITICAL CARE MED. 2547, 2551 (2006) (citing insufficient physician training in communication of bad news as a barrier to the provision of high quality care for the terminally ill) [hereinafter Nelson et al.]; PerryUndem, Physicians' Views Toward Advance Care Planning and End-of-Life Care Conversations: Findings From A National Survey of Physicians Who Regularly Treat Patients 65 and Older, JOHN A. HARTFORD FOUND. 1, 4 (April 2016) (noting only 29\% of physician poll respondents reported having had training in end-of-life discussions and $46 \%$ said they were unsure say they frequently or sometimes feel unsure of what to say during them).

99. GAWANDE, supra note 96, at 167-68 ("You worry far more about being overly pessimistic than you do about being overly optimistic."); see also Nancy L. Keating, et al., Physician Factors Associated With Discussions About End-of-Life Care, CANCER, 1, 4 (2010) (concluding that most physicians surveyed indicated that they would not discuss end of life decisions and choices with terminally ill patients un- 
duly optimistic about prognosis or potential efficacy of therapy, ${ }^{100}$ and some physicians admit to lying to patients during discussions of prognosis. $^{101}$

There is good reason to try to reverse these trends and communicate openly and honestly about prognosis and potential for therapeutic efficacy, and the intercession of palliative care specialists can help. Talking with patients about end-of-life preferences while patients are still receiving therapeutic interventions can help patients confront death or at least consider that they may not survive their illness, and research suggests that this sort of conversation is not stressful per se. ${ }^{102}$ These discussions also can assist patients in making more informed choices about whether and how to proceed with treatment versus focusing on palliation of symptoms. The American Society of Clinical Oncology has noted the importance of patients' understanding of their prognosis and the benefits and risks of treatment. ${ }^{103}$ Thus, it

til they exhibited symptoms or there were no remaining treatments available) [hereinafter Keating et al.].

100. See Nicholas A. Christakis \& Elizabeth B. Lamont, Extent and Determinants of Error in Doctors' Prognoses in Terminally Ill Patients: Prospective Cohort Study, 320 BRIT. MED. J. 469, 470-71 (2000) (finding that, in predicting patients' remaining life expectancies, physicians were correct only $20 \%$ of the time and were overoptimistic $63 \%$ of the time and concluding that a closer doctor-patient relationship was associated with over-optimistic predictions); Elizabeth B. Lamont \& Nicholas A. Christakis, Prognostic Disclosure to Patients with Cancer Near the End of Life, 134 ANNALS INTERNAL MED. 1096, 1096-1102 (2001) (finding that, in communicating expected survival times to patients with terminal cancer, physicians were frank with patients only $37 \%$ of the time, provided deliberately inaccurate survival estimates $40.3 \%$ of the time and preferred to offer no estimate for $22.7 \%$ of the patients studied. The authors concluded that "for all of these patients, physicians were able and willing to formulate objective prognoses, whether accurate or not, but had difficulty communicating them, even to insistent patients.").

101. See Lisa I. Lezzoni, et al., Survey Shows That at Least Some Physicians Are Not Always Open or Honest with Patients, 31 HeALTH AfFAIRS 383, 383-86 (2012) (finding that one in ten physicians admitted to lying to a patient within the previous year, and over half acknowledged that they had been unreasonably optimistic about a patient's prognosis).

102. See Ezekiel J. Emanuel et al., Talking with Terminally Ill Patients and Their Caregivers About Death, Dying, and Bereavement, 164 ARCH. INTERN MED. 1999, 200103 (2004) (observing that these discussions during serious illness can be emotionally helpful to both patients and caregivers and concluding, based on survey data, that most patients did not report significant added stress as a result of these conversations); see also Timothy E. Quill, Initiating End-of-Life Discussions with Seriously Ill Patients: Addressing the "Elephant in the Room," 284 J. AM. MED. ASSN. 2502, 250304 (2000) (stating that many physicians feel that end-of-life treatment options should be discussed early to be meaningful and providing a list of clinical indications for discussing end-of-life care) [hereinafter Quill].

103. See Thomas J. Smith et al., American Society of Clinical Oncology Provisional Clinical Opinion: The Integration of Palliative Care into Standard Oncology Care, $30 \mathrm{~J}$. CLINICAL ONCOLOGY 880, 882 (2012). 
recommends a "working list of components" that might include "a description of the diagnosis; a frank discussion of the prognosis (with a reasonable forecast of survival) and curability; explicit discussion of the medically appropriate goals of treatment; use of a standardized symptom assessment tool, ... psychosocial assessment and support; and involvement of hospice early in the remaining lifetime of patients with a life-ending illness (for example, an informational visit three to six months before the person is expected to die)." ${ }^{\prime 104}$ As an aspirational list of talking points, this "working list" is excellent, but research suggests that these conversations do not happen as frequently or as soon as recommended. . $^{105}$

Physicians may worry that discussing these matters with patients will generate anxiety or may give the patient or family the idea that the physician is abandoning the patient's care. The occasional patient or family member who, upon hearing the word "hospice," reacts angrily and accuses the physician of giving up on the patient may discourage physicians from raising the topic spontaneously, even when the physician believes that the timing is appropriate. ${ }^{106}$ Nevertheless, physicians must recognize the importance of these conversations and proceed gently and with sensitivity to the patient's and family's ability to process relevant information. ${ }^{107}$ When done well, these discussions can provide a pathway to earlier utilization of palliative medicine and hospice, while avoiding unwanted or aggressive care and its accompanying adverse effects. Physicians, however, understandably find such discussions difficult and appear to resist such conversations

104. Id.

105. Id.

106. See Kevin B. O'Reilly, How to Talk About Hospice Care, AM. MED. News (Mar. 18, 2013), http://www.amednews.com/article/20130318/profession/1303 $19945 / 4 /$.

107. Dale G. Larson \& Daniel R. Tobin, End-of-Life Conversations: Evolving Practice and Theory, 284 JAMA 1573, 1575 (2000) (observing that "discussing palliative care issues while disease-remitting treatments are continued without creating a perception of abandonment requires the utmost empathy and skill") [hereinafter Larson \& Tobin]. Cf. Steven Z. Pantilat, Communicating With Seriously Ill Patients: Better Words to Say, 301 JAMA 1279, 1279 (2009) (explaining that recent research on physician-patient communication emphasizes the value of a model that involves multiple conversations over time and that offers the prospect of continued care, even if active therapy to cure the disease no longer makes sense); Quill, supra note 102 , at 2503 ("[T]imely, sensitive discussions with seriously ill patients regarding medical, psychosocial, and spiritual needs at the end of life are both an obligation of and privilege for every physician."). 
until therapeutic options are exhausted or the patient indicates a desire to abandon treatment. ${ }^{\text {ios }}$

Still, these skills can be taught and learned, and there is now substantial effort from a variety of stakeholders to provide content and programs to practicing physicians. For example, the American Society of Clinical Oncology's "best practices" model recommends a series of conversations with patients with terminal cancer diagnoses, with content to reflect the patient's evolving medical condition. ${ }^{109}$ This recommendation is consistent with the reality of terminal illness-that patients' situations evolve over time, that prognosis and response to therapy are not predictable, and that, therefore, a series of conversations at various decision points makes good sense.

In addition to providing comfort care to address physically and emotionally distressing symptoms, the presence of an active palliative care team can help to bridge the communication gap between clinicians and patients and among patients and their families. With respect to patients and families, palliative care teams can help to frame decisions and options, explain risks and benefits of available options based on sound evidence, and offer different ways to approach decision-making for seriously ill patients. ${ }^{10}$ Clinicians who refer patients to palliative care services that include communication support appreciate help with delivering bad news and discussing end-of-life planning."'1

108. See Keating et al., supra note 99, at 3-4; see also Corita Grudzen, At the End of Life, Sometimes Less is More, 171 ARCH. INTERN MED. 1201, 1201 (2011) (acknowledging recent treatment of a patient in which the author and physician was "managing her from one crisis to the next, without real pause to discuss her wishes or her prognosis").

109. See Thomas J. Smith et al., American Society of Clinical Oncology Provisional Clinical Opinion: The Integration of Palliative Care into Standard Oncology Care, $30 \mathrm{~J}$. CLINICAL ONCOLOGY 880, 882 (2012). Other organizations, such as the American Academy on Communication in Healthcare and the Association for Behavioral Sciences in Medical Education, also have developed evidence-based clinical teaching exercises designed to improve physician-patient communication about challenging topics such as when to cease therapeutic care or how to convey bad news. See, e.g., AM. ACAD. ON COMM. IN HEALTHCARE, Mission \& Vision, http:/ /www. aachonline.org/About-AACH/Mission-Vision (last visited Sept. 21, 2017); ASS'N BEHAV. SCI. AND MED. EDUC., http:/ / www.absame.org/dcms/about (last visited Sept. 21, 2017) (providing information and resources for medical school and continuing medical education curricula).

110. See Powers, supra note 21, at 6 ("[T]his work required, in varying degrees, time, patience, and diplomacy.").

111. Id. (explaining that successful palliative care collaborations with referring clinicians and patients and families can help to "direct[] everyone's energy toward the best possible outcomes for patients"). 
One 2009 study demonstrates the challenges and rewards of training physicians to integrate the discussion about and provision of palliative care into their practices when caring for seriously ill cancer patients. ${ }^{12}$ In a semi-structured qualitative interview study of thirtyfive oncology clinicians who had previously participated in a clinical trial to integrate concurrent palliative care with oncology care, ${ }^{113}$ responses suggested that participants gained insight into the challenges of introducing palliative care early in the process of caring for their patients. ${ }^{14}$ Participating clinicians described several thematic "lessons" learned from their participation in the primary study: caring for the whole patient; understanding quality versus quantity of life goals and communicating with patients accordingly; dealing with patients who "just want to fight"; helping with transitions from disease-focused to palliative treatment by introducing palliative care early in the treatment process; appreciating the importance of early referral to a palliative care team for patients with advanced cancer; and recognizing the need for decision support. ${ }^{115}$ Clinicians also reported learning about the need for appropriate timing of the palliative care consult and the importance of differentiating between palliative care and hospice when introducing palliative care to patients and families. ${ }^{116}$ In fact, several clinicians came to view palliative care teams as co-managers of the patients' illnesses and found that introducing palliative care early in the treatment relationship reduced patients' perceptions of "abrupt transitions which might be perceived as being abandonment." ${ }^{117}$ Finally, par-

112. See Marie Bakitas et al., The Project ENABLE II Randomized Controlled Trial to Improve Palliative Care for Rural Patients with Advanced Cancer: Baseline Findings, Methodological Challenges, and Solutions, 7 PALLIATIVE SUPPORT CARE 75, 75-86 (2009) (highlighting results of the primary study).

113. Id.

114. See Marie Bakitas et al., Oncologists' Perspectives on Concurrent Palliative Care in an NCI-Designated Comprehensive Cancer Center, 11 PALLIATIVE SUPPORT CARE 1, 1-9 (2013), https: / / www.ncbi.nlm.nih.gov/pubmed/23040412 [hereinafter Perspectives on Palliative Care].

115. See generally id. (describing oncologists' self-assessment of what they had learned about integrating palliative care with therapeutic care early in the process of treating patients with advanced cancer).

116. See id. at 5 (describing some clinicians whose patients equated palliative care with hospice and the challenges of assuring these patients that they were not "giving up" on the patient); see also Nada Fadul et al., Supportive Versus Palliative Care: What's In a Name?, 115 CANCER 2013, 2016 (2009) (discussing the common misunderstanding of palliative care as being "hospice" and thus creating a barrier to early introduction of PC and finding that oncologists themselves preferred to use the term "supportive care" rather than "palliative care" with cancer patients at various stages of treatment).

117. See Perspectives on Palliative Care, supra note 114, at 6 . 
ticipating clinicians also reported personal benefit from involving palliative care teams when discussing difficult information about prognosis with patients and families."18 In sum, this follow-up study of clinicians who participated in the primary therapeutic and palliative care integration study amply demonstrates the benefits of training oncologists and other cancer clinicians about the multi-faceted role that palliative care teams can play in the care of seriously ill patients and families. The same lessons surely would apply in the context of other specialties that routinely care for seriously ill patients.

\section{B. Interdisciplinary Teamwork and Interprofessionalism}

The current system creates an artificial dichotomy between curative and palliative care as well as perpetuating a divide between palliative and hospice care. Physicians who practice in the "curative" role tend to focus on clinical problem solving, will continue to advocate for therapy even when the prognosis is grim, and may often view death as a failure. Physicians who practice in the "palliative care" role focus on the patient as a whole person rather than as a disease diagnosis and will view unnecessary suffering at the end of life as a failure. When care for a seriously ill patient integrates curative goals (for as long as they are clinically appropriate) with palliative goals, the patient, the family, and the physicians are better off. There is no reason to keep these goals separate or to provide these two types of care only sequentially. ${ }^{119}$

Perhaps most relevant in the context of the therapy/palliative care dichotomy, medical education generally lags behind in teaching the benefits of integrated palliative care across a variety of specialties. Physicians are reluctant to discuss treatment choices in the broader context of patient preferences and realistic predictions of prognosis, in part because medical education still emphasizes therapy (with the goal of curing the patient) as opposed to care of the patient as a whole. ${ }^{120}$ There is little pedagogical focus in medical schools on end-of-

118. Id. at 8 (explaining that oncologists vary in their abilities and comfort with communicating information about serious illness and that some clinicians find more satisfaction in learning and utilizing good communication techniques than others).

119. See generally Laura P. Gelfman \& Diane E. Meier, Making the Case for Palliative Care: An Opportunity for Health Care Reform, 8 J. HEALTH \& BIOMEDICAL L. 57 (2012); see generally Perspectives on Palliative Care, supra note 114.

120. J. Andrew Billings \& Susan Block, Palliative Care in Undergraduate Medical Education: Status Report and Future Directions, 278 J. AM. MED. ASs'N. 733, 734 (1997) 
life care, including palliative and hospice care. ${ }^{121}$ The predominant medical school curricula still fail to focus on "care," a broader term that is not exclusively about preserving life, but rather about caring for the patient in optimal ways and alleviating suffering, even when illness is severe or death imminent. ${ }^{122}$ The common training of physicians focuses instead on fighting disease, treating this goal as a problem to be solved while remaining detached, but this approach has the potential to obscure the patient and his goals as an individual. ${ }^{123}$

Palliative care has only been recognized as an approved medical specialty since 2007, though the practice of palliative medicine has caught on quickly in hospitals. ${ }^{124}$ While the specialty has spread widely, the practice of palliative care and its integration with therapeutic care are often perceived to be very much at odds with the cure-at-all-

(describing the rarity of education in end-of-life care in both medical schools and residency programs); see DYING IN AMERICA, supra note 18, at S-11 (noting that "hospice and palliative care are generally absent from the usual curricula of medical and nursing schools" and recommending that "[e]ducational institutions ... establish the appropriate training ... to strengthen the palliative care knowledge and skills of all clinicians who care for individuals with advanced serious illness who are nearing the end of life"); see Kelley \& Morrison, supra note 20, at 753 (explaining that "core palliative care competences of communication, pain and symptom management, and psychosocial assessment remain, at best, a small part of most medical school and residency training programs").

121. See Kelley \& Morrison, supra note 20, at 753.

122. Ellen Fox, Predominance of the Curative Model of Medical Care: A Residual Problem, 278 J. AM. MED. Ass'N. 761, 761 (1997) (explaining that, while curative care is important, palliative care is also an important goal of medicine); see Johanna Shapiro, Walking a Mile in Their Patients' Shoes: Empathy and Othering in Medical Students' Education, 3 PHIL., ETHICS, AND HUMAN. IN MED. 1, 5 (2008) (explaining that the presumption that illness can be cured is part of a "vast enterprise to protect the healthy from the ill, to reassure the healthy that they will not become ill; or if they do unfortunately cross over into the kingdom of the sick, to ensure that they can be fixed and returned to normalcy") [hereinafter Shapiro].

123. See Susan D. Block, Medical Education in End-of-Life Care: The Status of Reform, 5 J. PALliative MED. 243, 243-48 (2002) (discussing the deficiencies in both formal curricula and informal medical training in care for the dying); Shapiro, supra note 122, at 5; cf. Daniel Callahan, Death and the Research Imperative, 342 NEW ENG. J. MED. 654, 654-55 (2000) (quoting William Haseltine, then CEO of Human Genome Sciences, as saying that "[d]eath is a series of preventable diseases" and arguing that research "should not, even implicitly, have eradication of death as its goal" because it supplants emphasis on the importance of relieving suffering at the end of life and it "promotes the idea among the public and physicians that death represents a failure of medicine").

124. See Paula Span, In Palliative Care, Comfort is the Top Priority, N.Y. TIMES (Feb. 12, 2016), https: / / www.nytimes.com/2016/02/16/health/in-palliative-carecomfort-is-the-top-priority.html. 
costs approach to care prevalent in American medical training and practice. ${ }^{125}$

With these challenges in mind, medical schools and health care institutions must make greater efforts to facilitate integrated palliative and therapeutic care through a combination of physician training, payment incentives, and institutional protocols to provide timely and robust palliative care services. A variety of guidelines and protocols have been published or are in development to assist at the institutional level. For example, one professional association has published a report to guide hospital ICUs in responding to the palliative care needs of the sickest patients. ${ }^{126}$ There are also good resources to guide nonpalliative care specialists when addressing distressing symptoms in their seriously ill patients, ${ }^{127}$ and these are particularly important given that access to specialized palliative care is uneven and in some places unavailable. ${ }^{128}$

In addition to training physicians directly about the nature of palliative care and the importance of introducing this care early in the treatment of seriously ill patients, educational and health care institutions and professional societies may encourage the utilization of palliative care through the recent move toward training in interprofessional practice. Training in interprofessional practice refers to a relatively recent effort to train professionals of different health-related professions to collaborate in order to deliver high-quality health care. ${ }^{199}$ As

125. Jessica Nutik Zitter, They Call Me 'Dr. Kevorkian', N.Y. TIMES (Nov. 14, 2013, 1:37 PM), http://well.blogs.nytimes.com/2013/11/14/they-call-me-drkevorkian/ (noting one palliative care specialist describes the ICU as a place "where a Wild West culture makes it a challenge for palliative care to get a foothold," adding that it is difficult "to slow a wild horse, particularly one that believes it can outrace death" and also adding that she "believe[s] in letting the dying determine how and when they die, as opposed to coaxing their organs at all costs").

126. See, e.g., Judith E. Nelson et al., Integration of Palliative Care in the Context of Rapid Response: A Report from the Improving Palliative Care in the ICU Advisory Board, 147 CHEST 560, 565 (2015).

127. See generally Craig D. Blinderman \& J. Andrew Billings, Comfort Care for Patients Dying in the Hospital, 373 NEW ENG. J. MED. 2549 (2015) (providing explicit and practical advice for non-palliative care specialists to address symptoms such as pain, dyspnea, cough and dry mouth, nausea, constipation, cachexia, fever, anxiety and insomnia).

128. See R. Sean Morrison et al., America's Care of Serious Illness: A State-by-State Report Card on Access to Palliative Care in Our Nation's Hospitals (2008), http:// www.capc.org/reportcard/state-by-state-report-card.pdf (identifying "notable disparities in geographical availability" of such programs and "strikingly low rates of palliative care programs in public and sole community provider hospitals").

129. See Interprofessional Education Collaborative Expert Panel, Core Competences for Interprofessional Collaborative Practice: Report of an Expert Panel, AMERICAN ASS'N 
defined by the World Health Organization, interprofessionalism, or collaborative medical practice among different health-related specialties, "happens when multiple health workers from different professional backgrounds work together with patients, families, carers and communities to deliver the highest quality of care." ${ }^{\prime 100}$ Relevant health professionals can include physicians, nurses, pharmacists, dentists, experts in public health, and more. Recent efforts to promote an interprofessional approach to health care focus on educating students in the health professions to work together across fields in order to exchange and build on shared and specialized competencies. ${ }^{13}$

Many end-of-life care programs already are team-based. For example, the "Dignity-Driven Decision Making" model aims to improve technical quality of care (including patient and family experience), while also improving population health and reducing costs. ${ }^{122}$ Similarly, the Coalition to Transform Advanced Care seeks to improve models for the delivery of care to people with advanced illness. ${ }^{133}$ In a more targeted sense, the "Respecting Choices" program improves palliative care by promoting community-wide advance care planning. ${ }^{134}$

Interprofessional education celebrates and prepares students to embrace the team-based approach that characterizes palliative care, especially hospice. The very essence of palliative care is its multiprofessional, interdisciplinary teamwork. ${ }^{135}$ The Medicare hospice regulations driving payment for and structure of hospice care require that it provide not only physician and nursing services but also drugs, medical supplies, short-term inpatient and respite care, homemaker

OF COLLEGES OF NURSING 1, 2 (2011), http://www.aacn.nche.edu/educationresources/ipecreport.pdf.

130. See Framework for Action on Interprofessional Education and Collaborative Practice, WHO 7 (2010), http: / / www.who.int/ hrh/resources/framework_action/en/.

131. See Core Competences for Interprofessional Collaborative Practice: Report of an Expert Panel, INTERPROFESSIONAL EDUCATION COLLABORATIVE EXPERT PANEL 3-5 (2011), http: / / www.aacn.nche.edu/education-resources/ipecreport.pdf.

132. See generally Bruce C. Vladeck \& Erin Westphal, Dignity-Driven Decision Making: A Compelling Strategy for Improving Care for People with Advanced Illness, 31 HEALTH AFFAIRS 1269 (2012).

133. See CoAlition to TRANSForm AdVANCED CARE \& AHIP Found., THE ADVANCED CARE PROJECT (2015), http: / / www.thectac.org/wp-content/uploads / 2015/06/ACP-Report-6-18-15-FINAL.pdf (discussing the benefits of PC and advocating quality improvement through structure, process, and outcome metrics, along with changes in payment systems to promote utilization).

134. See RESPECTING CHOICES, ABOUT Us, http://respectingchoices.org/ about_us (last visited Sept. 21, 2017).

135. See supra notes 17, 18, 26, 31, 33, 44, 48, 103, 112, 120, 125, and accompanying notes. See also DYING IN AMERICA, supra note 18, at 2-21, 2-22. 
and home health aide services, counseling, social work services, and physical, occupational, and speech/language therapy. ${ }^{136}$ Palliative care is the optimal vehicle for educators to use to achieve the core competencies of interprofessional collaborative practice, not only among health care professional students but also with students in such varied professions as chaplaincy and social work. ${ }^{137}$

Payment policy reflects and intersects with the interprofessonalism education movement, through its recent movement away from traditional fee-for-service practice and toward value-based practice. Both accountable care organizations (ACOs) and patient-centered medical homes (PCMHs) illustrate the point. ACOs are voluntarily organized groups of physicians and other health care professionals, and perhaps health care institutions, which take on not only the task of caring for patients but also some of the financial risk attendant to seeking payment for that care. ${ }^{138}$ Because of the financial risk they assume, ACOs are incentivized to better coordinate health care, thus improving the timeliness of various health procedures while avoiding unnecessary care and reducing the risk of iatrogenesis. ${ }^{139}$ By definition, they require the ability to work with professionals of all sorts to best coordinate patients' care.

On the primary care level, PCMHs similarly require interprofessional practice and are intended to serve the same goals. ${ }^{100}$ Unlike ACOs, which tend to incorporate capitated or aggregate payments, ${ }^{1,1}$

136. See 42 C.F.R. § 418.202 (2018).

137. See generally Cynthia Forrest \& Christina Derrick, Interdisciplinary Education in End-of-Life Care: Creating New Opportunities for Social Work, Nursing, and Clinical Pastoral Education Students, 6 J. SOC. WORK IN END-OF-LIFE \& PALL. CARE 91 (2010).

138. See Grant B. Smith et al., The Role of Palliative Care in Population Management and Accountable Care Organizations, 18 J. PALL. MED. 486, 487 (2015) (characterizing ACOs as incentivizing high-value care and efficiency "by aligning reimbursement with patient outcomes through capitated and/or aggregated payments") [hereinafter G. Smith].

139. See Accountable Care Organizations (ACO)s: General Information, CENTERS FOR MEDICARE AND MEDICAID SERVICES, https://innovation.cms.gov/initiatives/ ACO (last visited Sept. 21, 2017); Advance Payment Accountable Care Organization (ACO) Model, CENTERS FOR MEDICARE AND MEDICAID SERVICES (2013), https: / / innovation.cms.gov/Files/ fact-sheet/ Advanced-Payment-ACO-ModelFact-Sheet.pdf.

140. See AMERICAN ACADEMY OF FAMILY PHYSICIANS (AAFP), Joint Principles of Patient-Centered Medical Home (2007), http://www.aafp.org/dam/AAFP/ documents / practice_management/pcmh/initiatives/PCMHJoint.pdf.

141. G. Smith, supra note 138 , at 487 . 
PCMHs tend to structure payment on a fee-for service basis. ${ }^{12}$ At least one major academic medical center has reported positive cost and quality outcomes after incorporating palliative care into its outpatient academic family medicine patient-centered medical home. ${ }^{1.3}$

Incorporation of palliative care into ACOs and PCMHs thus illustrates the operation of an interprofessional, team-based practice within a corporate structure that itself requires interprofessional teamwork. Palliative care supports both of the primary goals of those corporate structures: improving quality and reducing cost. ${ }^{14}$ For example, a retrospective study of decedents who had been patients of an ACO within three New York counties demonstrated that patients enrolled in the ACO's home-based palliative care program experienced fewer hospital admissions, more frequently enrolled in hospice care, and generated significantly less total Medicare cost than patients in the ACO who were not enrolled in that program..$^{15}$ Importantly, given that most Americans wish to die at home, ${ }^{146} 87 \%$ of patients in the pro-

142. See Samuel T. Edwards et al., Patient-Centered Medical Home Initiatives Expanded in 2009-13: Providers, Patients, and Payment Incentives Increased, 33 HEALTH AFFAIRS 1823, 1827 (2014) (reporting that all but two of the initiatives investigated used standard or enhanced fee-for-service payments accompanied by pay-forperformance bonuses, capitation payments or both).

143. See David J. Wallenstein, Palliative Care in the Patient-Centered Medical Home, 39 PRIMARY CARE CLINIC OFFICE PRAC. 627 (2012) (describing PCMH at the University of California, Los Angeles).

144. See Mark T. Hughes \& Thomas J. Smith, The Growth of Palliative Care in the United States, 35 ANN. REV. OF PUB. HEALTH 459, 463-65 (2014) [hereinafter Hughes \& Smith]; see also Cassel et al., supra note 53, at 745 (presenting the business case for hospitals to invest in palliative care).

145. See Siew Tzuh Tang, When Death Is Imminent: Where Terminally Ill Patients with Cancer Prefer to Die and Why, 26 CANCER NURSING 245, 249 (2003) (noting nearly ninety percent of terminally ill cancer patients would choose to die at home); Judith C. Hays et al., Preference for Place of Death in a Continuing Care Retirement Community, 41 GERONTOLOGIST 123, 123 (2001) ("Most patients in the United States would prefer to die at home ....") (citations omitted) [hereinafter Tang]; Susan W. Tolle et al., Oregon's Low In-Hospital Death Rates: What Determines Where People Die and Satisfaction with Decisions on Place of Death?, 130 ANNALS INTERNAL MED. 681, 681 (1999) ("Surveys indicate that most Americans would prefer to die at home or in a homelike setting ....") (citations omitted). But see Catherine J. Jones, Assistance in Dying: Accounting for Difference, 19 W. NEW ENG. L. REV. 405, 412 (1997) (providing that now all patients want to die at home and noting, "a peaceful, accepted death, at home with family present" is "a white, middle class death"). As with many issues surrounding death and dying, cultural background may influence this desire. Patients of some Asian cultures, for example, may wish to die in an institution. See id. ("Those of Chinese descent may not want to die at home because of cultural beliefs that their ghost will haunt the place where they died, and they do not want to impose that on their family.") (citation omitted). For a discussion of cultural differences, although limited to African-American and Hispanic cultures, see Perez \& Cerminara, supra note 3.

146. See Tang, supra note 145 , at 249 . 
gram died at home, thus presumably in the location and the manner they wished." Separately, a meta-analysis of a series of randomized trials of palliative care performed by Kaiser Permanente revealed that the palliative care studied in each trial improved at least one of the following outcomes: symptoms, quality of life, mood, satisfaction, resource use, advance care planning, survival, and costs. ${ }^{1 \text { is }}$ Similarly, the Sutter Health Program of Advanced Illness Management integrated home visits and an emphasis on advance care planning into the medical care provided to seriously ill patients. ${ }^{19}$ Patient, family, and physician satisfaction increased, and admissions, ICU days, and inpatient length of stay all decreased significantly..$^{150}$

Finally, interprofessionalism involving attorneys in addition to members of various medical specialties can be very useful in facilitating access to good palliative care. The proliferation of medical-legal partnerships (MLPs) promises to improve medical care by resolving legal issues arising in connection with the social determinants of health. ${ }^{\text {sin }}$ Concerns about the social determinants of health should resonate with palliative care professionals because of the field's emphasis on treating the whole patient, including anxiety and distress in addition to physical symptoms and pain. Both MLPs and palliative care are inherently interprofessional and thus well-suited to combining interprofessionally..$^{152}$ Seriously ill patients may endure multiple nonmedical sources of distress such as loss of their jobs; loss of health in-

147. Lustbader et al., supra note 64, at 3; see also Pallavi Kumar et al., Family Perspectives on Hospice Care Experiences of Patients With Cancer, 35 J. CLIN. ONCOL. 432 (2016).

148. Press Release, Kaiser Permanente, KAISER PERMANENTE STUDY LiNKS HOSPITAL-BASED PALLIATIVE CARE WITH IMPROVED QUALITY AND HIGHER PATIENT SATISFACTION (Jun. 27, 2011).

149. Lustbader, supra note 64 , at 4 .

150. Hughes \& Smith, supra note 144 , at 463 (reporting a reduction of $54 \%$ in admissions, $80 \%$ in ICU days, and $26 \%$ (two days) in length of stay.).

151. See Ellen M. Lawton \& Megan Sandel, Investing in Legal Prevention: Connecting Access to Civil Justice and Healthcare Through Medical-Legal Partnership, $35 \mathrm{~J}$. LEGAL MED. 29 (2014); Lynn Hallarman et al., Blueprint for Success: Translating Innovations from the Field of Palliative Medicine to the Medical-Legal Partnership, $29 \mathrm{~J}$. LEGAL MED. 179 (2014) [hereinafter Hallarman et al.]; Lynn Hallarman \& Denise Snow, The Medical-Legal Partnership: An Alliance Between Doctors and Lawyers in the Care of Patient-Clients with Advanced Life-Limiting Illness, 17 NYSBA HEALTH L. J. 44 (2012) [hereinafter An Alliance Between Lawyers and Doctors]. Regarding palliative care within the MLP setting, see Lynn Hallarman \& Denise Snow, The Medical-Legal Partnership: Addressing Medical-Legal Suffering for Patients with Advanced Illness \#245, 15 J. Palliative MeD. 123 (2012); Kerry J. Rodabaugh et al., A Medical-Legal Partnership as a Component of a Palliative Care Model, 13 J. PALLIATIVE MED. 15 (2010).

152. Hallarman et al., supra note 151, at 179-80, $186 \mathrm{tbl} 7$. 
surance; medical debt; food, housing or energy insecurity; and family decompensation and deterioration. Many of these are matters with which an attorney can assist. ${ }^{153}$ One physician proponent of palliative care medical-legal partnerships, for example, has described a case in which a terminally ill cancer patient expressed extreme concern about the well-being of her daughter after her death. ${ }^{154}$ The palliative care team involved legal counsel in the MLP, and counsel was able to ease the patient's concerns by having the patient's parents named as her child's temporary guardian, with an eye toward permanent guardianship after the patient's death..$^{155}$ The patient told her care team that she felt "deep relief" that her child would be safe after her death and died about a week later..$^{156}$ The MLP attorney ensured that her parents became the child's permanent guardians after the patient's death. ${ }^{15}$

Attorneys in MLPs have been able to ease patients' existential pain by handling such arrangements for minor children, applications for disability benefits and food stamps, health insurance coverage disputes, and execution of advance directives and wills, among other matters. ${ }^{158}$ In a study described as the first "to examine if MLP services can reduce perceived stress and concerns of patients in a familymedicine-based patient-centered medical home," researchers at an MLP within an academic medical center found "large improvements in both well-being and perceived stress scores after receipt of legal intervention." ${ }^{159}$ Even after accounting for other stressors in the patients' lives during the time period studied, the researchers described the results as "suggest[ing] that MLPs may be a valuable intervention for reducing stress and improving well-being among vulnerable populations." ${ }^{\prime 160}$

Even outside of a formal MLP structure, close collaboration with attorneys as part of cancer care teams benefits patients, providers, and health care institutions. Patients who receive legal support during

153. See An Alliance Between Lawyers and Doctors, supra note 151, at 45 (incorporating the work of Eric Cassell into a proposed definition of "medical-legal suffering": "[t]he stripping of personhood by the inability to resolve problems "created or aggravated' by advanced or disabling illness").

154. Id.

155. Id.

156. Id.

157. Id. at $44-46$

158. Anne M. Ryan et al., Pilot Study of Impact of Medical-Legal Partnership Services on Patients' Perceived Stress and Wellbeing, 23 J. HeAlTH CARE FOR THE POOR AND UNDERSERVED 1536, 1543 fig. 2 (2012).

159. Id. at $1545,1542$.

160. Id. at 1543 . 
cancer treatment report reduced stress and improved ability to navigate financial obstacles to medical care. ${ }^{161}$ Providers whose patients are relieved of employment, housing, financial, and other legal concerns are better able to design and optimize treatment plans on an effective clinical timeline. ${ }^{12}$ Health care institutions also benefit from reductions in missed appointments and interruptions in treatment that might otherwise arise without legal assistance to avoid them. ${ }^{163}$

\section{Eliminating the Artificial Payment Distinction}

The appropriate use of palliative care and timely transition to hospice for terminally ill patients thus makes good clinical and business sense, but the medical profession and educational institutions must invest in increased training and development of the ability to work interprofessionally to fully embrace it. Health care payment policy changes also are in order. CMS's approval of billing codes for advance care planning sessions establishes a significant precedent. By acknowledging that advance care planning is a valuable part of medical practice, worthy of being reimbursed, CMS has acknowledged the importance of honesty in physician-patient communication about impending death, and of health care professional facilitation of planning for the end of life.

CMS should proceed further in transforming billing and coding, in recognition of research indicating that " $[\mathrm{r}$ ]eimbursement processes can both enable and impede care delivery across different regions and populations." ${ }^{\prime 16}$ For example, to facilitate the provision of palliative care even as therapy proceeds, institutions operating on a fee-forservice model should be able to bill for the services of affiliated professionals such as chaplains and social workers, ${ }^{165}$ who form an integral part of palliative care teams. The same is true regarding billing for such non-medical professional services as part of outpatient palliative care. One way to do this is to authorize billing codes for those services, while another way would be to bundle those services into a comprehensive code. The point is that we should patch such holes in the fabric of our reimbursement system, or even better, weave a com-

161. See Steward B. Fleishman et al., The Attorney as the Newest Member of the Cancer Treatment Team, 24 J. CLINICAL ONCOLOGY 2123, 2124-25 (2006).

162. See id. at 2125.

163. See id.

164. Lee et al., supra note 49 , at 6 .

165. Cf. Cassell et al., supra note 53 , at 745. 
prehensive tapestry of palliative care service billing for health care professionals and all members of the requisite interprofessional team.

Finally, in order to facilitate the interdisciplinary teamwork approach to palliative and therapeutic care described above, it will also be necessary to amend laws affecting payment to eliminate the artificial dichotomy between therapeutic or palliative and hospice care. The ACA authorized demonstration projects designed to do just that, which are currently ongoing. ${ }^{166}$ The data from those studies, assuming it matches the previously existing literature analyzed below, should unequivocally point to authorizing payment for concurrent, or openaccess, hospice benefits.

Insurers and vertically integrated health care providers have studied concurrent care for more than a decade. In 2004, for example, Aetna piloted a hospice benefit design change combined with a comprehensive case management program..$^{167}$ It began covering hospice costs for twelve months rather than the typical six months before death, even as nurse case managers with training in palliative care reached out to and educated patients, families, and caregivers about advance directives and a variety of palliative care services. ${ }^{168}$ It also paid for curative treatment at the same time as it paid for hospice services and eliminated limits on length of inpatient hospice stay and coverage for outpatient hospice care, among other liberalization of benefits. ${ }^{1.9}$ Other studies have involved palliative care transition programs in Southern California, ${ }^{100}$ integration of early palliative care with standard cancer treatment in Boston, ${ }^{17}$ and an advanced illness management program in San Francisco. ${ }^{1 / 2}$ All covered palliative care con-

166. MEDICARE CARE CHOICES MODEL, https: / / innovation.cms.gov/initiatives / Medicare-care-Choices (last visited Sept. 21, 2017).

167. Claire M. Spettell et al., A Comprehensive Case Management Program to Improve Palliative Care, 12 J. PALLIATVE MED. 827, 827-28 (2009) [hereinafter Spettell et al.].

168. Id.

169. Id. at 828

170. See Richard D. Brumley et al., Effectiveness of a Home-Based Palliative Care Program for End-of-Life, 6 J. PALLIATIVE MED. 715, 715 (2003) [hereinafter Brumley et al.].

171. Temel, supra note 32.

172. Elizabeth L. Ciemins et al., An Evaluation of the Advanced Illness Management (AIM) Program: Increasing Hospice Utilization in the San Francisco Bay Area, 9 J. PALliative MeD. 1401, 1401 (2006); see also Harris Meyer, Changing the Conversation in California About Care Near the End of Life, 30 HEALTH AFFAIRS 390, 390 (2011) (describing same program) [hereinafter Ciemins]. 
currently with curative treatment, in the name of beginning to provide the benefits of palliative care earlier in the disease process.

The results of these studies provided strong evidence in support of the concurrent care demonstration programs ACA has authorized. Both clinical and economic benefits were observed. First, eliminating the false dichotomy in payment between curative treatment and palliative care helps eliminate provider confusion and patient hope-fueled reluctance to elect hospice care. ${ }^{173}$ Second, it "may encourage hospice utilization in racial and ethnic groups that have not traditionally embraced hospice care. ${ }^{\prime \prime 14}$ The program in San Francisco, for example, involved three groups of terminally ill patients: those participating in the program being studied, those receiving the usual care from the same home healthcare workers as the first group (Usual Group 1), and those receiving the usual care from a different group of health care workers (Usual Group 2). ${ }^{175}$ Hospice election among African-American patients receiving concurrent care in that program was $60 \%$ greater than among African-American patients receiving care in Usual Group $1{ }^{176}$ The differential was $73 \%$ when comparing election of hospice care among African-American patients receiving concurrent care with election among those in Usual Group 2." The overall percentage of African-American patients accessing hospice in the program approached the percentage of Caucasians accessing hospice in the program-a startling statistic because African-Americans typically access hospice care at a much lower rate than Caucasian patients. ${ }^{17 s}$

Moreover, early access to palliative care benefits patients and their families physically and mentally. It can result in longer life for patients, as demonstrated by numerous studies such as that of terminally ill patients with non-small-cell lung cancer receiving early access to palliative care, who survived approximately two months longer than patients in a control group. ${ }^{199}$ It is also better for the mental health

173. Perez \& Cerminara, supra note 3, at 291.

174. See Cerminara, supra note 14 , at 455 .

175. Ciemins, supra note 172 , at $1407-08$.

176. Id.

177. Id.

178. Perez \& Cerminara, supra note 3, at 257-58.

179. See Temel, supra note 32, at 739-41 (also documenting "clinically meaningful improvements in quality of life and mood" and patients' charts that reflected ... resuscitation preferences more often than the charts of the other group). 
of those family caregivers, ${ }^{\text {,so }}$ and can help ease conflicts, guilt, and strain on relationships near the end of life. ${ }^{\text {sit }}$

Supplementing this clinical data is evidence that concurrent care is cost-effective. The Aetna researchers discovered that patients exposed to palliative care earlier in the disease process used hospice care more than others and that utilization of acute and critical care decreased among study participants. ${ }^{122}$ The cost of care for the patients in the Southern California study control group was almost double that of the patients with early access, while the patients with early access were significantly more satisfied with their care than the others were. ${ }^{183}$ Most hospitals and other facilities incorporating hospice among their services face greater and greater financial stress in today's health care system, so both they and health care payors should welcome concurrent care as a way to reduce health care costs while providing highquality care. Even better, value-based purchasing, widely agreed to be the future of health care payment, incentivizes the provision of better health care, achieved here by the above-described reductions in stress, anxiety, and associated conditions, and the resulting longer life of better quality, that accompanies concurrent care.

\section{Conclusion}

Approaching the end of life after suffering through the terminal phase of an illness should not resemble falling off a cliff to drop precipitously to death. Today's health care system is characterized by overutilization of iatrogenically harmful therapeutic interventions near the end of life, long past the time when those interventions do more good than harm to both body and soul. As a result, far too many patients access the multiple benefits of palliative care, especially hospice care, only when they are on the precipice of death. Inadequate

180. See Alexi A. Wright et al., Associations Between End-of-Life Discussions, Patient Mental Health Care, Medical Care Near Death, and Caregiver Bereavement Adjustment, 300 J. AM. MED. ASs'N. 1665, 1670-71 (2008); Elizabeth H. Bradley et al., Depression Among Surviving Caregivers: Does Length of Hospice Enrollment Matter?, 161 AM. J. PSYCHIATRY 2257, 2259 (2004) (finding that 24.1\% of caregivers of patients spending three or fewer days in hospice met diagnostic criteria for major depressive disorder as compared with only nine percent of caregivers of patients with longer hospice enrollment).

181. See Sharla Wells-DiGregorio, Family End-of-Life Decision Making, in DECISION MAKING NEAR THE END OF LIFE: ISSUES, DEVELOPMENTS, AND FUTURE DiRECTIONS 247 (James L. Werth, Jr. \& Dean Blevins eds., 2009).

182. Spettel et al., supra note 167 , at 831 .

183. Brumley et al., supra note 170, at 720-21. 
training in discussing terminal prognoses and care options combines with a desire to avoid the appearance of patient abandonment, leaving physicians uncertain about how to proceed when facing patients with terminal illnesses and their families.

To improve the process of dying for both patients and providers, our health care system should train and incentivize health care professionals to progress seamlessly from therapeutic interventions through timely palliative and hospice care, to inevitable death. Medical and continuing medical education should increase the focus on developing the skill of discussing "bad news," including terminal prognoses and end-of-life choices, with patients and their families. Such education should incorporate and build upon nascent efforts to ensure that students in the health professions are prepared for interprofessional practice, respecting and collaborating closely in team-based treatment, including palliative care, and including attorneys as part of medicallegal partnerships when appropriate.

Finally, CMS should do what it can to improve the fractured and complex Medicare billing and coding system also utilized by private insurers. Approval of billing codes for advance care planning discussions represents a good start. Future initiatives should include efforts to facilitate the provision of care in interprofessional teams including professionals other than medical personnel in order to help patients and families navigate the complex health care system with as much assurance and minimized stress as possible. Most important on the immediate horizon is the authorization of reimbursement for concurrent care, or open-access hospice after analyzing the results of current Medicare demonstration projects. Elimination of billing distinctions such as the artificial border between fee-for-service therapeutic and palliative care and per diem hospice care will go a long way toward the ultimate goal: the smoothest path possible from diagnosis to death. 
